\title{
The lethal multiple congenital anomaly syndrome of polydactyly, sex reversal, renal hypoplasia, and unilobular lungs
}

\author{
D DONNAI*, I D YOUNG $\dagger$, W G OWEN \\ P F W MILLER $\S$, AND W F KNOX* \\ From * the Departments of Medical Genetics and Pathology, St Mary's Hospital, Manchester; †the \\ Department of Child Health, Leicester Royal Infirmary, Leicester; $¥$ the Department of Pathology and \\ Paediatrics, Royal Preston Hospital; Preston; and \$the Department of Paediatrics, Oldham and District \\ General Hospital, Oldham.
}

SUMmaRY Three cases are reported of a lethal multiple congenital anomaly syndrome. The infants had moderate limb shortening, joint contractures, polydactyly, and the two with male karyotypes had female external genitalia. Internal anomalies included unilobular lungs, hypoplasia of the anterior portion of the tongue, and renal hypoplasia.

We report three unrelated infants with a lethal multiple congenital anomaly (MCA) syndrome who had moderately short limbs, polydactyly, and valgus deformity of the feet with syndactyly. All had female external genitalia but two had 46,XY karyotypes. All cases had micrognathia and microglossia and at necropsy unilobular lungs and renal hypoplasia were found. We consider that these infants have the lethal MCA syndrome recently described by Rutledge $e t a l^{1}$ and that the two sibs described by Kohler ${ }^{2}$ as probably having the SmithLemli-Opitz syndrome ${ }^{3}$ also have this condition. Although documentation is sometimes incomplete, other reported cases ${ }^{4-8}$ are also likely to have been affected.

\section{Case reports}

CASE 1

This apparently female infant was born at 35 weeks' gestation, the first child of a healthy, unrelated, Caucasian 26 year old woman and 30 year old man. The mother had had a healthy baby and a termination of pregnancy in a previous relationship. In this pregnancy urinary and serum oestriols were low when measured between 32 and 35 weeks' gestation, but human placental lactogens were normal. The baby, which had female external genitalia, died of respiratory failure at the age of $1 \frac{1 / 2}{2}$ hours.

The baby weighed $2.325 \mathrm{~g}$, length $45 \mathrm{~cm}$, occipito-

Received for publication 28 May 1985

Revised version accepted for publication 2 September 1985. frontal circumference (OFC) $30 \mathrm{~cm}$. The limbs appeared to have moderate rhizomelic shortening (fig 1), there were bilateral transverse palmar

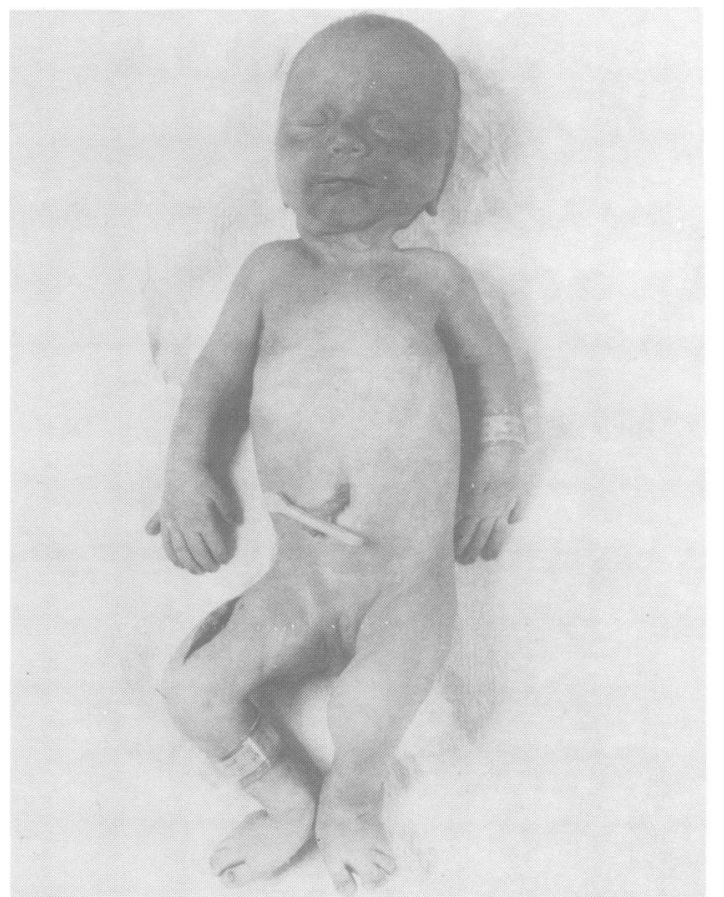

FIG 1 Case 1 postmortem. Note rhizomelic limb shortening and female external genitalia. 
creases, short thumbs, and postaxial hexadactyly of the hands (fig 2). There was limited abduction of the hips and marked calcaneovalgus deformity of the feet with complete soft tissue syndactyly of the second and third toes (fig 3). Bilateral cateracts were present, the chin was small, and the soft palate absent.

At necropsy the posterior two-thirds of the tongue was bulky and the anterior one-third shortened. The larynx appeared normal but the left lung was unilobular and the right lung bilobular.

There was a high interventricular septal defect of the heart and the left kidney was extremely hypo- plastic ( $1 \mathrm{~g})$; the right kidney weighed $10 \mathrm{~g}$ and appeared normal. Histological sections of the left kidney showed normal glomeruli.

There was a transparent, thin, flat sheet of tissue behind the bladder which was thought to represent the uterus. From this led normal looking tubes and the gonads which histologically were found to be testes.

The only other internal abnormalities found were excessive length and dilatation of the descending and sigmoid colon. Histologically, prominent nerve fibres were found in the submucosal and intermuscular layers but ganglion cells were not found.

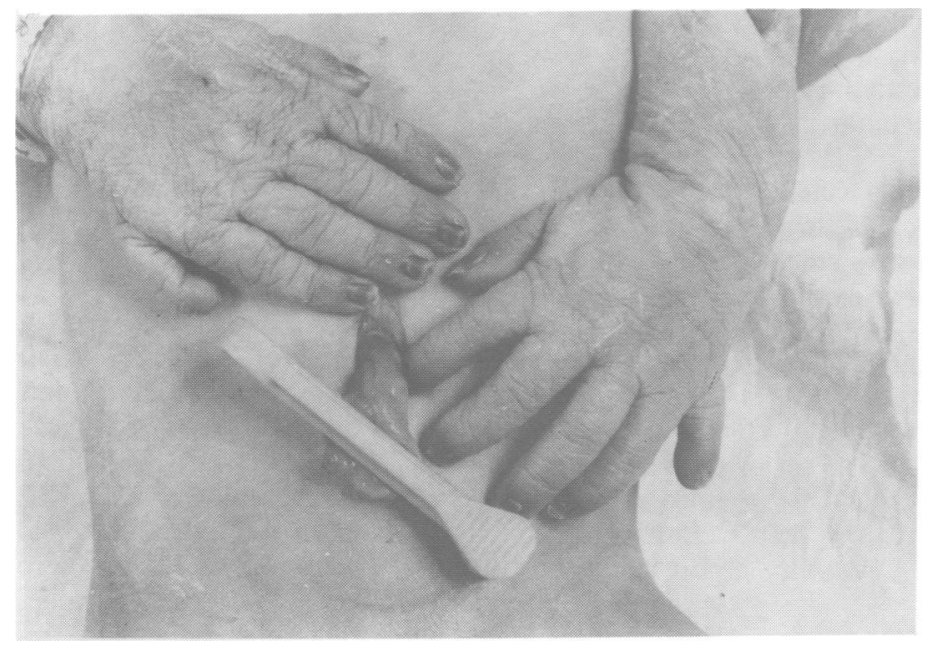

FIG 2 Case 1. Note postaxial hexadactyly and proximal placement of thumbs.

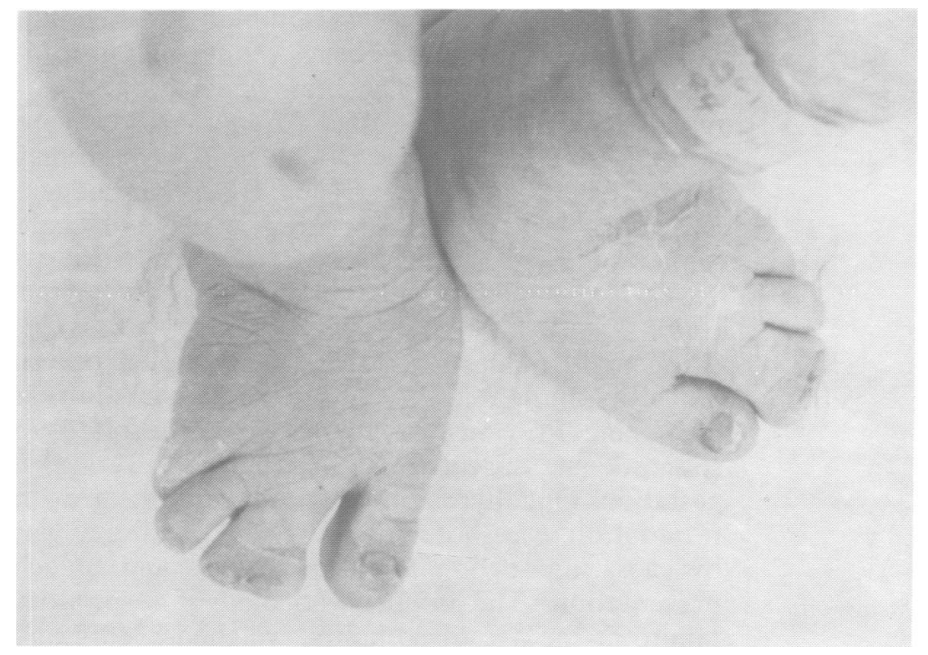

FIG 3 Case 1. Note valgus deformity, syndactyly 2/3, and short halluces. 
Histological sections of the pancreas showed increased size of islets.

Chromosome analysis of cultured blood lymphocytes and fibroblasts from a skin biopsy showed a normal male karyotype, 46,XY.

\section{CASE 2}

This phenotypically female Caucasian baby was born at 38 weeks' gestation and was the product of the tenth pregnancy of a 41 year old father and 38 year old mother, who were healthy and unrelated. Three previous pregnancies had resulted in normal infants, two girls and one boy. The other six pregnancies had resulted in miscarriages at 12 weeks.

The mother took no drugs during the pregnancy and felt well throughout. However, during the last four weeks urinary oestriol levels were measured on 12 separate occasions and were always either very low or unrecordable. Serum human placental lactogen levels were normal.

The baby, who lived only four hours, had a weight of $1890 \mathrm{~g}$, length $41 \mathrm{~cm}$, and OFC $30 \mathrm{~cm}$. Ultrasonography shortly before death showed very small kidneys. She had an abnormal facies (figs 4 and 5) with a prominent capillary naevus on the forehead, anteverted nares, low set ears, cleft soft palate, small tongue with thick alveolar margins, and

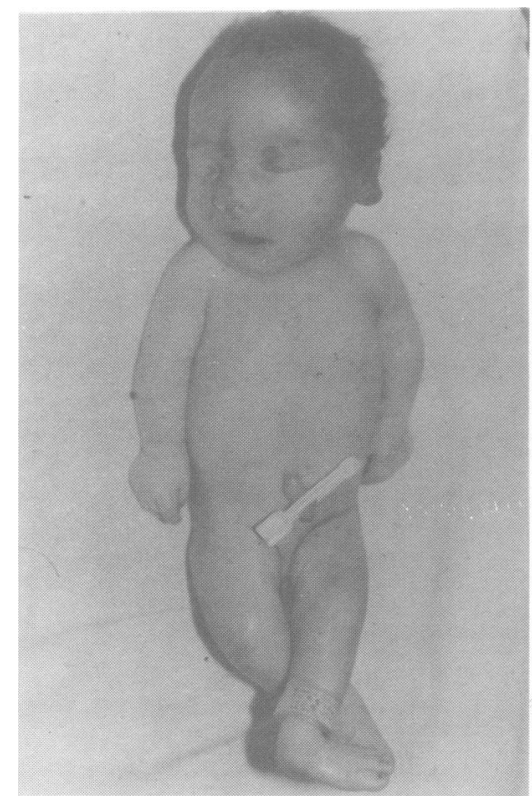

FIG 4 Case 2. Note limb shortening, abnormal facies, and haemangioma.

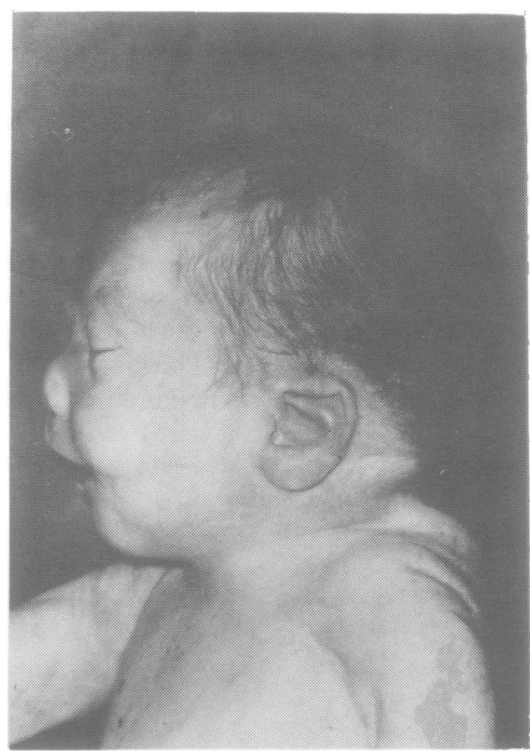

FIG 5 Case 2. Note micrognathia and short neck.

marked micrognathia. Her neck was short with a loose fold of skin posteriorly. Her hands had small thumbs, proximally placed index fingers, and a left single palmar crease. Both feet showed severe calcaneovalgus with syndactyly of the second and third toes, complete on the right and partial on the left (fig 6). The right foot also showed postaxial polysyndactyly. Both hips were dislocated and there was reduced range of movement at the left knee. Both arms showed moderate mesomelic and rhizomelic shortening. The external genitalia were female.

At necropsy both lungs were unilobular. Seminal vesicles and undescended testes (confirmed histologically) were present. The brain, heart, and abdominal viscera including the adrenal glands were normal macroscopically. No histological studies were carried out on these organs. Blood lymphocyte and fibroblast cultures showed a normal male karyotype, 46,XY.

CASE 3

This female infant was born at 40 weeks' gestation to a healthy, unrelated 21 year old woman and 26 year old man. Previous pregnancies had resulted in spontaneous miscarriages at 10 and 12 weeks' gestation. Oligohydramnios and intrauterine growth retardation were noted in pregnancy. Delivery was by caesarian section for fetal distress and breech presentation. The infant, who died of respiratory failure at the age of 30 hours, weighed $2320 \mathrm{~g}$ and 


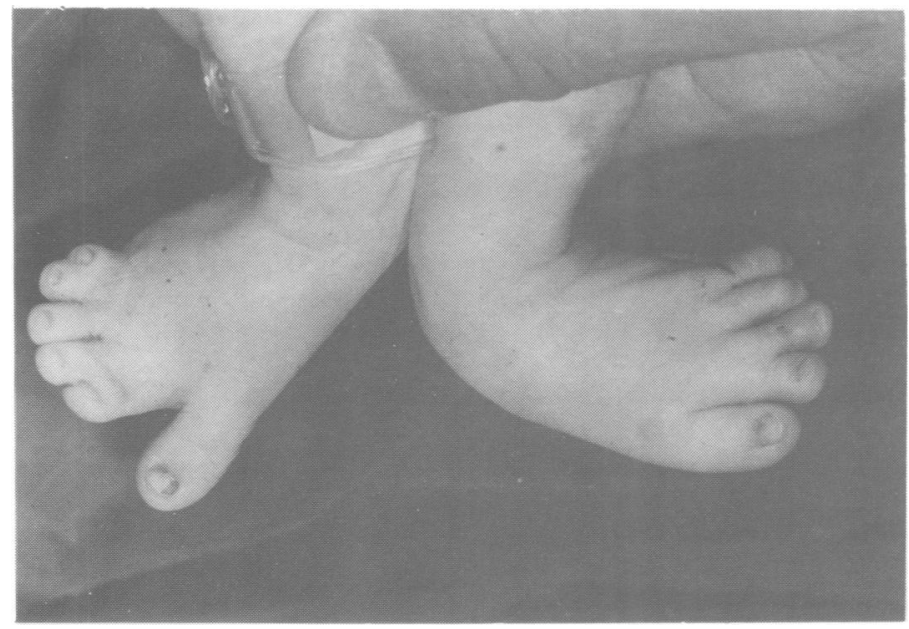

FIG 6 Case 2. Note valgus deformity, syndactyly, and polydactyly.

had a crown-rump length of $29 \mathrm{~cm}$, crown-heel length $41 \mathrm{~cm}$, OFC $33 \mathrm{~cm}$. There was rhizomelic and mesomelic shortening of all limbs (fig 7) with limited joint movements. The shoulders were internally rotated, there was a limited range of movements at elbows and wrists, and the hands were clenched with flexion deformity of the metacarpophalangeal joints. Bilateral transverse palmar creases were present and the thumbs were short and proximally placed. There was limited hip abduction, marked suprapubic and inguinal skin creases, limited movement at the knees, and metatarsus valgus. Both first metatarsals were short and there was postaxial polydactyly on the left foot with syndactyly between the fifth and sixth toes (fig 8). The occiput was prominent and the neck short. Multiple haemangiomata were present over the glabella, eyelids, philtrum, and temples. The corneae were cloudy but no cataracts were seen. The nose was short with anteverted nares and there was marked micrognathia (fig 9). The gum margins were broad and the tongue very short anteriorly but no cysts were present. The palate was high arched and cleft (fig 10). At necropsy the left cardiac ventricle was hypoplastic with a high ventricular septal defect and overriding aorta. There was only one pulmonary vein on each side draining into a hypoplastic left atrium, and the inferior vena cava was left sided passing anterior to the hilum of the left lung to enter the right atrium. Both lungs were unilobular but not hypoplastic (right $19 \mathrm{~g}$, left $14.7 \mathrm{~g}$ ). The larynx was small. The kidneys were both hypoplastic; the right had three pyramids and weighed $4.5 \mathrm{~g}$ and the left had two pyramids and weighed $4.6 \mathrm{~g}$. The other abdominal organs were present and macroscopically normal with female internal genitalia. The brain was macroscopically normal although the posterior fossa was shallow.

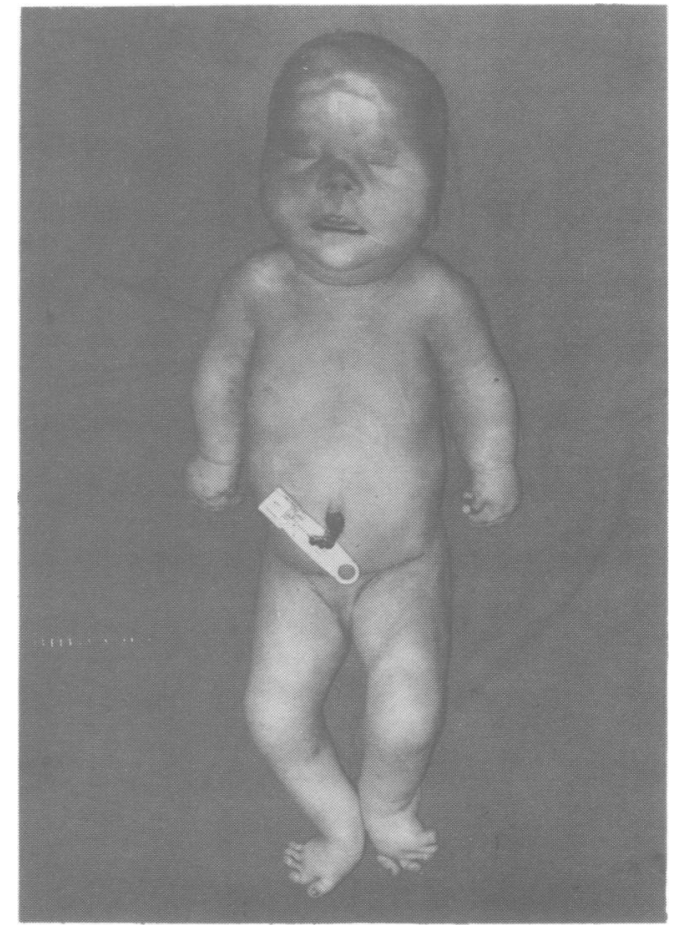

FIG 7 Case 3. Note limb shortening, abnormal facies, haemangioma, and inguinal skin creases. 


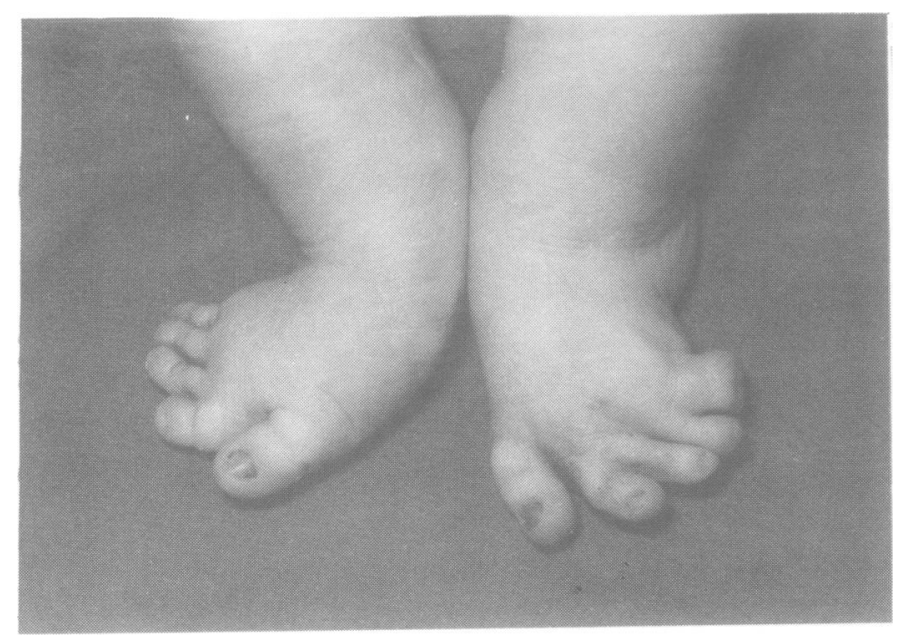

FIG 8 Case 3. Note valgus deformity, short halluces, and polysyndactyly.

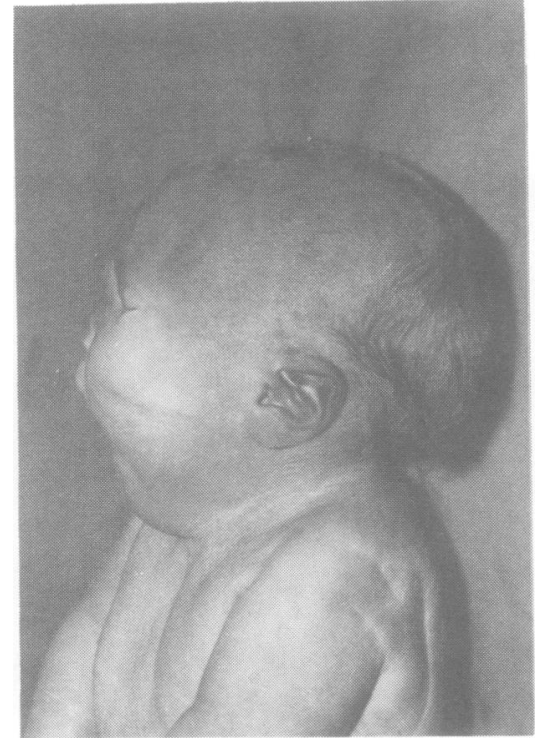

FIG 9 Case 3. Note micrognathia, short neck, and short nose.

Histological examination of the pancreas revealed increased size and number of islets. There was aganglionosis of all the large bowel and part of the terminal ileum involving the appendix. Ovarian and renal tissue was microscopically normal. Chromosome analysis showed a normal female karyotype, $46, \mathrm{XX}$

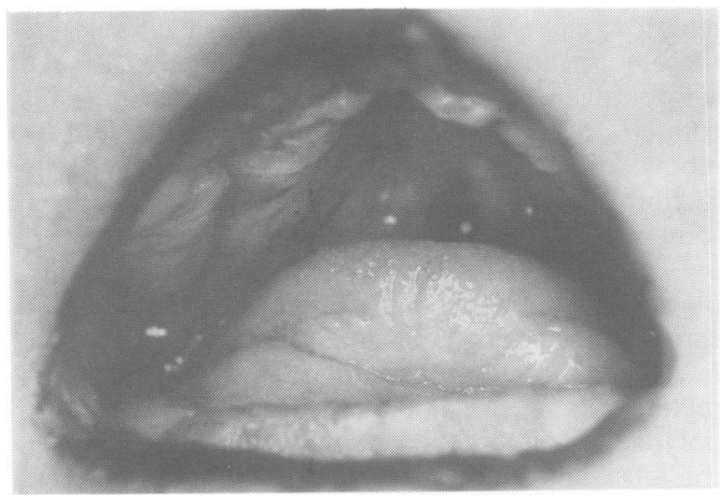

FIG 10 Case 3. Note thick upper alveolar margin, cleft palate, and very short anterior portion of the tongue.

\section{Discussion}

The three cases reported here show a very similar pattern of internal and external abnormalities to the three cases (two of them sibs) reported by Rutledge et al. ${ }^{1}$ We consider that the sibs reported by Kohler ${ }^{2}$ bear more similarities to those of Rutledge et al ${ }^{1}$ and those contained in this report than to the SmithLemli-Opitz syndrome. ${ }^{3}$ The table shows the main clinical features of the eight cases. Early death was the rule and in the four cases which were male on karyotyping or on testicular histology, there were female or ambiguous external genitalia. In all cases where it was specifically stated, the limbs were reported to be moderately short. There was a 
TABLE Clinical and pathological features of cases.

\begin{tabular}{|c|c|c|c|c|c|c|c|c|c|}
\hline & Rutledg & et al $^{l}$ & & Kohler ${ }^{2}$ & & This re & & & Total \\
\hline & $\begin{array}{l}\text { Case } \\
1\end{array}$ & 2 & 3 & Case & 2 & Case & , & 3 & \\
\hline & & $s$ & & Sibs & & & & & \\
\hline Gestation (wk) & 40 & 37 & 40 & 38 & 38 & 35 & 38 & 40 & \\
\hline Birth weight (g) & 2580 & 1880 & 2150 & 3107 & 2767 & 2325 & 1890 & 2320 & \\
\hline Age at death & $1 \mathrm{~d}$ & $1 \mathrm{~d}$ & $14 \mathrm{~d}$ & $6 \mathrm{~h}$ & $15 \mathrm{~h}$ & $11 / 2 \mathrm{~h}$ & $4 \mathrm{~h}$ & $30 \mathrm{~h}$ & \\
\hline External genitalia & $\mathrm{F}$ & $\mathrm{F}$ & Ambig & $\mathrm{F}$ & $\mathrm{F}$ & $\mathrm{F}$ & $\mathrm{F}$ & $\mathrm{F}$ & \\
\hline Karyotype & $46 . X X$ & $46, X X$ & $46 . X Y$ & $\begin{array}{l}\text { Testes } \\
\text { at } \\
\text { necropsy }\end{array}$ & $\begin{array}{l}\text { 'Female' } \\
\text { at } \\
\text { necropsy }\end{array}$ & $46 . X Y$ & $46 . X Y$ & $46, \mathrm{XX}$ & \\
\hline Short limbs & + & + & $?$ & $?$ & + & + & + & + & $6 / 6$ \\
\hline Hands & & & & & & & & & \\
\hline Postaxial polydactyly & - & + & + & + & + & + & - & - & $5 / 8$ \\
\hline Short thumbs & + & $?$ & $?$ & $?$ & + & + & + & + & $5 / 5$ \\
\hline Transverse palmar crease & + & + & + & $?$ & ? & + & + & + & $6 / 6$ \\
\hline Feet & & & & & & & & & \\
\hline Valgus deformity & + & + & Varus & + & + & + & + & + & $7 / 8$ \\
\hline Syndactyly of toes & + & + & + & + & + & + & + & + & $8 / 8$ \\
\hline Postaxial polydactyly & - & - & + & + & + & - & + & + & $5 / 8$ \\
\hline Cataracts & - & - & + & $?$ & $?$ & + & - & - & $2 / 6$ \\
\hline Low set ears & + & $?$ & + & ? & + & - & + & + & $5 / 6$ \\
\hline Micrognathia & + & + & + & $?$ & + & + & + & + & $7 / 7$ \\
\hline Cleft/absent soft palate & - & - & - & + & - & + & + & + & $4 / 8$ \\
\hline Microglossia & + & + & + & $?$ & ? & + & + & + & $6 / 6$ \\
\hline Tongue cysts & + & + & + & $?$ & $?$ & - & - & - & $3 / 6$ \\
\hline Unilobular lungs & + & + & $?$ & + & + & + & + & + & $7 / 7$ \\
\hline Cardiac defect & + & + & $?$ & + & + & + & - & + & $6 / 7$ \\
\hline Hypoplastic kidney(s) & + & + & + & + & $?$ & + & + & + & $7 / 7$ \\
\hline Cerebellar hypoplasia & + & + & + & $?$ & ? & - & - & - & $3 / 6$ \\
\hline Gall bladder agenesis & + & - & $?$ & $?$ & $?$ & - & - & - & $1 / 5$ \\
\hline Pancreatic islets & $\uparrow \begin{array}{l}\text { Islets, } \\
\text { no }\end{array}$ & $\uparrow \begin{array}{l}\text { Islet } \\
\text { cells }\end{array}$ & $\begin{array}{l}\text { No } \\
\text { necropsy }\end{array}$ & $\uparrow \begin{array}{l}\text { Size } \\
\text { giant }\end{array}$ & $\uparrow \begin{array}{l}\text { Size } \\
\text { giant }\end{array}$ & $\uparrow \begin{array}{l}\text { Size } \\
\text { islets }\end{array}$ & $?$ & $\uparrow \begin{array}{l}\text { Size } \\
\text { islets }\end{array}$ & $6 / 6$ \\
\hline & $\begin{array}{l}\text { giant } \\
\text { cells }\end{array}$ & & & cells & & & & & \\
\hline
\end{tabular}

characteristic valgus deformity of the feet in all but case 3 of Rutledge et $a l^{1}$ and syndactyly between several toes. There was postaxial polydactyly in all cases of the hands or feet or both.

An unusual abnormality noted in the cases of Rutledge et $a l^{1}$ and our three cases was the small tongue; this was not commented on in the report of Kohler. ${ }^{2}$ Cleft or absent soft palate was noted in case 1 of Kohler ${ }^{2}$ and all cases in this report, and cataracts in case 3 of Rutledge et al ${ }^{1}$ and case 1 in this report. Unilobular lungs are an unusual finding in malformation syndromes and were present in all seven cases subjected to necropsy. Hypoplastic kidneys were present in all the necropsied cases and a cardiac defect in all but case 2 in this report. Aganglionosis was found in cases 1 and 3 in this report and may be a feature of this syndrome; large bowel histology is not available for case 2 and not reported by Rutledge et al ${ }^{1}$ or Kohler. ${ }^{2}$ A review of published reports of coexisting aganglionosis and Smith-Lemli-Opitz syndrome has revealed several other cases of this probably separate syndrome. Lowry et $a l^{4}$ reported a child with polydactyly, cardiac defects, and hypoplastic kidneys. Patterson et al $l^{5}$ reported a $46, X Y$ female with abnormal lung lobation, an abnormal kidney, but no polydactyly. Zizka et at reported two males with hypoplastic genitalia, joint contractures, polydactyly, and cardiac defects. Lipson and Hayes ${ }^{7}$ reported a male with ambiguous genitalia and polydactyly, and Greene et $a l^{8}$ reported two $46, \mathrm{XY}$ females with polydactyly and other features similar to the cases reported here. All of the cases with aganglionosis died, the longest survival being two months.

Rutledge et al ${ }^{1}$ considered several other lethal conditions in their differential diagnoses including the short rib-polydactyly syndromes, asphyxiating thoracic dystrophy, and the Ellis-Van Creveld syndrome. Like them, we dismissed these as unlikely because of the lack of characteristic radiographical and clinical features in our cases and the presence of other features not reported in those syndromes. Rutledge et al ${ }^{1}$ did consider the cases by Kohler ${ }^{2}$ in his differential diagnosis but rejected them since he considered that they did not have mesomelic dwarfing, tongue cysts, or laryngeal hypoplasia, and that 
the renal anomaly was different. In fact, Kohler ${ }^{2}$ reported that his case 2 had short limbs and his photographs confirm this. It is interesting to note that in Kohler's discussion he considered that his cases had a unique phenotype and it is only in the following editorial note that the possibility of Smith-Lemli-Opitz syndrome ${ }^{3}$ is introduced. In an editorial comment Lowry, ${ }^{9}$ agreeing with the suggestion of Smith-Lemli-Opitz syndrome ${ }^{3}$ for Kohler's cases, then goes on to consider phenotypic overlap between Smith-Lemli-Opitz, ${ }^{3}$ Meckel, ${ }^{10}$ and other syndromes. We believe that the cases reported and reviewed here bear such a strong resemblance to each other, and differ so markedly from the spectrum of clinical signs and clinical course usually associated with the Smith-Lemli-Opitz syndrome, ${ }^{3}$ that they should be considered as a separate malformation syndrome. In their review of the Meckel syndrome, Opitz and Howe ${ }^{10}$ cited two cases reported in German publications by Foerster and by Casper where the affected infants had renal hypoplasia and a pattern of abnormalities which would fit more closely with the syndrome reported here than with the Meckel syndrome. In the same paper, Opitz and Howe ${ }^{10}$ reviewed the UllrichFeichtiger syndrome; some of the cases discussed closely resemble this new syndrome although the authors stated that they are likely to be examples of the Smith-Lemli-Opitz syndrome. Pfeiffer ${ }^{11}$ illustrated a presumed case of the Ullrich-Feichtiger syndrome (his case 13). He reported affected sibs who died at 48 hours of age and had polydactyly, valgus deformity of the feet, and aplasia of the kidneys, with hypospadias in the male. The illustration of the affected male bears a strong resemblance to the cases reported here. Antley et al ${ }^{12}$ also considered Pfeiffer's case $13^{11}$ as a possible example of the $\mathrm{C}$ trigonocephaly syndrome. ${ }^{13}$

One of the most unusual but consistent features of this lethal multiple congenital anomaly syndrome appears to be the pulmonary segmentation defect. In the computerised dysmorphology data base ${ }^{14}$ seven syndromes are listed as having this abnormality. Two of these, Fryns et $a^{15}$ and Ivemark ${ }^{16}$ syndromes, do not have polydactyly as a feature and differ in other ways, so can be discounted. Five of the listed syndromes with pulmonary segmentation defect also have polydactyly as a feature: the anocerebrodigital syndrome of Hall et al, ${ }^{17}$ the C trigonocephaly syndrome,$^{13}$ the hydrolethalus syndrome, ${ }^{18}$ and the cases reported by Kohler ${ }^{2}$ and Rutledge et al. ${ }^{1}$

Joint contractures and short limbs, marked in cases 2 and 3 and mild in case 1 , probably represent the postnatal legacy of a prenatal lack of movement. The akinesia may have been due to 'splinting' of the limbs by oedema (thickening of subcutaneous tissue was noted on $x$-ray of case 3 ) or secondary to neurological impairment. Toriello et al ${ }^{19}$ have recently discussed the concept of the fetal akinesia sequence. Other conditions with joint contractures should be considered in the differential diagnosis: cerebro-oculo-facio-skeletal syndrome $(\mathrm{COFS})^{20}$ has features in common including cataracts, and PenaShokeir I syndrome ${ }^{21}$ shares pulmonary hypoplasia and early death.

Two other features are worthy of note. In the sibship of case 2 and case 3 of this report and in Kohler's ${ }^{2}$ cases there was a very striking history of miscarriage at around 10 to 14 weeks. This may relate to the second point, since in the present cases 1 and 2 maternal serum oestriol levels were persistently low during late pregnancy. In both cases serum human placental lactogen levels were normal. These observations, in conjunction with the sex reversal, would be consistent with a major metabolic defect in the fetal adrenals. Rutledge et $\boldsymbol{l}^{1}$ have speculated on the nature of a possible early error in morphogenesis common to many organs. The findings in our patients indicate that whatever the precise nature of the basic underlying defect, it is likely to extend to the adrenal glands also.

This report helps to establish the existence of a lethal malformation syndrome which has similarities to the Meckel syndrome and the $\mathrm{C}$ trigonocephaly syndrome but has sufficient differences to be considered as a separate condition. Four of the eight cases reported and reviewed here are sib pairs, suggesting an autosomal recessive mode of inheritance. The limb shortening, cardiac, and renal abnormalities might permit prenatal diagnosis by real time ultrasound scanning and the polydactyly, syndactyly, and cleft palate could serve as markers of the syndrome at fetoscopy.

The authors are grateful to $\mathrm{Mr}$ J F B Clarke for obstetric details of case 1, to Dr I Blumenthal for permission to report case 3 , and to Ms Susan Garnett for manuscript preparation.

\section{Note added in proof}

We propose that this syndrome be called the Lowry-Miller-Maclean syndrome, since theirs was the first full description of this disorder in 1968.

\footnotetext{
References

1 Rutledge JC, Friedman JM, Harrod MJE, et al. A new lethal multiple congenital anomaly syndrome. Am J Med Genet 1984;19:255-64.

2 Kohler HG. Brief clinical report: familial neonatally lethal syndrome of hypoplastic left heart, absent pulmonary lobation, polydactyly and talipes, probably Smith-Lemli-Opitz (RSH) syndrome. Am J Med Genet 1983;14:423-8.
} 
${ }^{3}$ Smith DW. Recognizable patterns of human malformation. 3rd ed. Philadelphia: Saunders, 1982:98-9.

${ }^{4}$ Lowry RB, Miller JR. Maclean JR. Micrognathia, polydactyly and cleft palate. J Pediatr 1968:72:859-61.

5 Patterson K. Toomey KE, Chandra RA. Hirschsprung disease in a $46 \mathrm{XY}$ phenotypic infant girl with Smith-Lemli-Opitz syndrome. J Pediatr 1983;103:425-7.

${ }^{6}$ Zizka J, Maresova J, Kerekes Z, Nozicka Z, Juttnerova V, Balicek P. Intestinal aganglionosis in the Smith-Lemli-Opitz syndrome. Acta Paediatr Scand 1983;72:141-3.

${ }^{7}$ Lipson A, Hayes A. Smith-Lemli-Opitz syndrome and Hirschsprung disease. J Pediatr 1984;105:177.

${ }^{*}$ Greene C. Pitts W. Rosenfeld R. Luzzatti L. Smith-LemliOpitz syndrome in two 46XY infants with female external genitalia. Clin Genet 1984;25:366-72.

9 Lowry RB. Editorial comment. Variability in the Smith-LemliOpitz syndrome: overlap with the Meckel syndrome. Am J Med Genet 1983:14:429-33.

${ }^{10}$ Opitz JM, Howe JJ. The Meckel syndrome (dysencephalia splanchnocystica, the Gruber syndrome). Birth Defects $1969 ; \mathbf{V}(2): 167-78$.

11 Pfeiffer RA. Associated deformities of the head and hands. Birth Defects 1969;5(3):18-34.

12 Antley RM, Do Sung Hwang, Theopold W, et al. Further delineation of the $\mathrm{C}$ (trigonocephaly) syndrome. Am J Med Genet 1981;9:147-63.

${ }^{13}$ Opitz JM, Johnson RC, McCreadie SR, Smith DW. The C syndrome of multiple congenital anomalies. Birth Defects 1969:5(2): 161-6.

14 Winter RM, Baraitser M, Douglas JM. A computerised data base for the diagnosis of rare dysmorphic syndromes. $J$ Med Genet 1984;21:121-3.

15 Fryns JP, Moerman F, Goddecris P. A new lethal syndrome with cloudy corneae, diaphragmatic defects and distal limb deformities. Hum Genet 1979;50:65-70.

${ }^{16}$ Ivemark BI. Implications of agenesis of the spleen on the pathogenesis of cono-truncus anomalies in childhood: analysis of the heart malformations in splenic agenesis syndrome, with fourteen new cases. Acta Paediatr Scand 1955;44(suppl 104):1110.

${ }^{17}$ Hall JG, Pallister PD, Clarren SK, et al. Congenital hypothalamic hamartoblastoma, hypopituitarism, imperforate anus and post-axial polydactyly - a new syndrome? Am J Med Genet 1980;7:47-74.

${ }^{18}$ Salonen R, Herva R, Reijo N. The hydrolethalus syndrome: delineation of a new lethal malformation syndrome based on 28 patients. Clin Genet 1981;19:321-30.

19 Toriello HV, Bauserman SC, Higgins JV. Sibs with the fetal akinesia sequence, fetal edema and malformations. Am J Med Genet 1985;21:271-7.

20 Pena SDJ, Shokeir MHK. Autosomal recessive cerebro-oculofacio-skeletal (COFS) syndrome. Clin Genet 1974:5:285-93.

${ }^{21}$ Pena SDJ, Shokeir MHK. Syndrome of camptodactyly, multiple ankyloses, facial anomalies and pulmonary hypoplasia: a lethal condition. J Pediatr 1974;85:373-5.

Correspondence and requests for reprints to $\mathrm{Dr}$ Dian Donnai, Department of Medical Genetics, St Mary's Hospital, Whitworth Park, Manchester M13 $0 \mathrm{JH}$. 